\title{
KAKS NOOREMAT LAENSÕNA
}

\author{
IRIS METSMÄGI
}

\section{klopp}

$\mathrm{S}$ õna klopp 'klots, pakuke' ei näi kirjakeeles just sage olevat, seletav sõnaraamat esitab üheainsa, Mait Metsanurgalt registreeritud kasutusnäite Hilja mängis põrandal laastude ja kloppidega (EKSS 2: 330). Murretes on sõna võrdlemisi hästi tuntud (Kuu VNg Jõh LNg Mar Var Kos KuuK Amb Koe VJg I Äks Ksi Plt Pil KJn M Ran Puh Võn Kam San Plv Räp), sel on häälikulised variandid klopp, kloṕp, lopp ja loṕp ning tähendused 1. 'puutükk, klots', nt puu klopid - - lapsed tegevad maeasid Mar, pista loṕp ala, kus tad vaja om Hls; 2. 'klotsikujuline ese või eseme osa', nt `Tel'jä klopp õli siesama mis [vankri] plokk Jõh, köie kokko 'laskmise klopp Kod, rihalse väravatel on sagarad, puust lopp kus sees `samma ots käib Pil; 3. (mustriruut); 4. 'lume-, jäätükk' (EMS III: 334). Seega avab murdesõnaraamat sõna tähenduse täpsemalt: see märgib kas õhemat puutükki, klotsi, mida sai näiteks mõnele esemele tasakaalustamiseks alla panna, või siis konkreetset detaili, kuhu midagi vahele pandi. Samades tähendustes tunneb sõna F. J. Wiedemanni sõnaraamat: klopp 'Klotz (zur Unterlage oder Befestigung)' ['klots (allapanekuks või kinnitamiseks)'] (1973: 311). Kaks viimast murdetähendust on kirja pandud vaid üksikutest murrakutest ja võivad olla juhuslikumat laadi tähendusnihked, välistada ei saa ka hoopis muud päritolu; need jäävad edaspidi vaatluse alt välja.

Sõna ei ole seni etümoloogide tähelepanu eriti pälvinud. Ainus selle sõna etümoloogia pärineb mulle teadaolevalt Alo Raunalt, kes peab seda eesti deskriptiivtüveks, kuid pakub samas välja ka võrdluse tegusõna kloppima tüvega, mille ta esitab alamsaksa laenuna, < kasks kloppen (Raun 1982: 43). Julius Mägiste sõnale etümoloogiat ei anna (EEW III: 869). Eesti etümoloogiasõnaraamatus lähtutakse Alo Rauna seisukohast ja määratletakse sõna klopp häälikuliselt ajendatud omatüvena. Mööndakse ka võimalust, et sama tüvi on sõnas kloppima, kui viimane on samuti häälikuliselt ajendatud (oma)tüvi, kuid usutavamaks peetakse sõna kloppima laenamist alamsaksa keelest (EES: 166).

Arvatavasti ei ole sõna klopp siiski eesti keeles spontaanselt tekkinud häälikuliselt ajendatud tüvi. Selles suhtes teeb ettevaatlikuks juba sõnaalguline konsonantühend. Semantilise seose puudumise tõttu ei ole sel sõnal tõenäoliselt ka etümoloogilist seost tegusõnaga kloppima, mille keskalamsaksa laenuallikas kloppen ja selle (ülem)saksa vaste klopfen omakorda just on onomatopoeetilise päritoluga (EWD 1: 672-673). Sõna klopp 'puutükk, klots; 
klotsikujuline ese või eseme osa' on ilmselt suhteliselt hiline eraldi laen, nt A. W. Hupeli sõnaraamatus (1818) see veel puudub. Tõenäoline laenuallikas on saksa Kloben, täpsemalt selle vanemas keeles esinenud variant Klobe (DWB), mille tänapäevased tähendused on 1. 'puupakk, lõhandik'; 2. TEHN 'väike höövelpink'; 3. 'konks; uksehing' (SES: 663); 'dicker, unförmiger Holzklotz, Schraubstock' ['paks vormitu puuklots, kruustangid'] (EWD 1: 672). Grimmide sõnaraamatus antakse sõna Klobe, Kloben üldtähenduseks 'etwas gespaltenes' ['miski lõhestatu']. Sõna ongi etümoloogiliselt seotud lõhkumist, lõhestamist märkiva tegusõnaga klieben (EWD 1: 672). Toodagu järgnevalt ära ka valik sõna Klobe, Kloben Grimmide sõnaraamatus esitatud täpsematest tähendustest (sõnaraamatu kirjaviis muutmata): 'gespaltenes holzstück, zum klemmen, festhalten' ['lõhestatud puutükk (vahele) pigistamiseks, kinni hoidmiseks']; 'klammerartige vorrichtungen zum festhalten' ['klambritaolised seadeldised kinnihoidmiseks'], a) 'eisenklammer' ['raudklamber'], b) '...ein instrument wie eine zange' ['tangidetaoline instrument'], c) an der thüre heiszt kloben das in die pfoste geschlagene zweischenkelige eisen worauf die klampe passt, und woran das anlegeschlosz hängt, auch die ähnlichen eisenstücke zwischen denen der riegel sich bewegt (Adelung) ['uksel on Kloben piida sisse löödud kaheharuline raud, millesse kramp sobib ja mille küljes ripub tabalukk [?], samuti sarnased raudosad, mille vahel liigub riiv']; '...ein losgespaltenes stück' ['lahtilõhutud tükk'], a) ein kloben holz 'groszes scheit' (Adelung) ['suur halg'], b) '...stück überhaupt' ['tükk üleüldse'], c) 'keule' ['nui, kurikas']; auch der spalt selbst hiesz früher so ['varem nimetati ka lõhet, pragu ennast nii'] (DWB: sub. Klobe, Kloben).

Semantiliselt ei ole eesti sõna klopp ja saksa sõna Kloben, Klobe seoses seega kahtlust. Mõnevõrra võib küsimusi tekitada häälikuline vastavus, sest saksa sõna ootuspärane eesti vaste oleks pika vokaaliga. Kuid ka pikavokaalne variant on eesti murretes tegelikult olemas. See esineb üksikutest murrakutest kirja pandud liitsõnas kloopsaag, variandid klopp-, luup- (EMS III: 332). Selle sõna saksa laenuallika, < sks Klobsäge, on välja toonud Ants Viires (1960: 61), hiljem on seda korranud Anu Haak, järelosis on asendatud varasema keskalamsaksa laenuga saag (Haak 1990: 354). Klobsäge on liitsõna Klobensäge 'eine grosze säge, holz zu dünnen bretern zu schneiden' ['suur saag puidu õhukesteks laudadeks lõikamiseks'] rööpvariant, see on olnud just tisleritööriist ja selle kasutamiseks on olnud vaja kahte inimest (DWB). Ka eesti kloppsaag märgib laudade ja plankude pikisaagimiseks kasutatud pingutamisnöörita raamsaagi keset raami selle tasapinna suhtes risti asuva saelehega, millega töötatakse kahe mehega (Viires 1960: 61): klopp`saega 'lõigata 'laiemad ja `pienemad puud 'lôhki Lüg, reissmassige tulep riips lavvale `pääle tõmmate, siis võip luup`saege siandsd õhukest 'lauda `saagi ku paper Krk (EMS III: 332). EMS annab tähenduseks 'kahemehesaag', mis ei ole muidugi vale, kuid osa tähendusest jääb tähelepanuta. Saksa liitsõna esiosis on kahtlemata sama sõna mis Kloben, viimati nimetatu seostamismotiivi kohta kõnealuse tööriistaga on pakutud kahte seletust, 1) kas lõhestatud käepidemete järgi, mis saelehte hoiavad, või 2) vahetult sõnast klieben 'lõhkuma, lõhestama', või sõnast Kloben 'klots', sest need moodustavad sae raami (DWB). Kui eesti keeles võib kõnealust tüve sisaldavas liitsõnas vokaali pikkus vahelduda (kloopsaag kloppsaag), siis ei tohiks olla kahtlust, et lühikese vokaaliga üksiktüvi klopp on sama päritoluga, lähtudes saksa sõnast Kloben, Klobe. 


\section{räsima}

Sõna räsima tähendab eesti kirjakeeles 'raputama, sasima, rebima (ja viga tegema); tallates, muljudes vm viisil rikkuma; (äkitselt) haarama, äsama' (EKSS 4: 930). Murretest on räsima kohta kirjapanekuid üle Eesti: EMSUKA andmeil Kuu Lüg Jõh IisR Muh Phl Rid Mar Kul Kse Han JõeK Amb Äks Lai Pst Ran Nõo Ote Rõn Kan Rõu. räsima tähendus on murretes mõnevõrra laiem kui kirjakeeles, kuid sellest üksikasjalikumalt edaspidi. Sõna näib olevat eesti keelde ilmunud suhteliselt hilja, puududes veel Wiedemanni sõnaraamatus (1893).

Sõna päritolu kohta on seni esitatud kaks seisukohta. Julius Mägiste ja Alo Rauna arvates on tegemist eesti deskriptiivtüvega (EEW 8: 2605; Raun 1982: 148). Mari Must (2000: 329-330) on sõna käsitlenud murdesõna resima variandina. Sõnade resima, räsima (ka kresima, reesima, rääsima, kräsima) ning nende kausatiivse $t a-$, $t \ddot{a}$-sufiksiga tuletiste põhitähendus eesti murretes on tema järgi 'lõikama, lõikuma, nüsima', peale selle esinevad veel tähendused 'kiskuma, (hammastega) rebima, tirima, rappima, purustama; kisklema, kaklema; rüselema; püüdlikult, ent tulemusvaeselt töötama'. Must peab sõnu resima räsima eespool nimetatud põhitähenduses vene laenuks, < vn pézamb 'lõikama; nikerdama, voolima; tapma, veristama; lõikavat valu tegema; sisse soonima; kiiresti v ägedasti toimima' (VES 2: 447). Tähenduse edasiarenemisel eesti murretes on mõju avaldanud häälikuliselt lähedased deskriptiivsed räselema, rässeldama jts (Must 2000: 330). Musta seisukohta resima ja räsima ühise päritolu ning vene laenuallika suhtes jagab ka Rogier Blokland (2009: 236, 245).

Sõna resima 'lõikama' puhul võib nimetatud vene laenuallikaga kahtlemata nõustuda, vastavus on nii häälikuliselt kui ka semantiliselt laitmatu. Ei ole siiski kindel, kas räsima 'raputama, sasima; (äkitselt) haarama, äsama' on sama päritoluga. Semantiline üleminek 'lõikama', ka 'tapma' > 'raputama; haarama' on ju kuidagiviisi kujutletav nt ühise tähenduskomponendi 'vigastama' alusel. Et vene laenuallikal tähendused 'raputama, sasima' ja 'haarama, äsama' puuduvad, siis peaks see tähendusareng olema toimunud eesti keeles. Väga usutav ikkagi ei tundu, et raputamisel, sasimisel võimalikult tekkivad kahjustused või vigastused seostuksid esmajärjekorras lõikamisega, vrd nt Vihm räsib vilja. Tuulest räsitud rannamännid. Paat, laev sai rajus kõvasti räsida. Koer räsib kassi. Kullist räsitud kana (EKSS 4: 930), liiatigi haaramine, nt Mees räsis kasti sülle (EKSS 4: 930). Kahtlust äratab ka asjaolu, et eesvokaalse räsima kõrval on samatähenduslik tagavokaalne rasima 'räsima, sasima' (EKSS 4: 729), mida häälikuliselt oleks vene sõnaga pésamı keeruline seostada. Variant rasima on tuntud murreteski, kuigi on vähem levinud kui räsima. Sõna on kirja pandud Mar Han Tõs Aud PJg Kei JõeK Sim Hel Nõo, tähendus on enamasti 'kisklema, rabelema, rüselema', paaril juhul 'sasima, rebima' (EMSUKA).

Sõnad räsima rasima võivadki olla teise päritoluga, kuigi samuti vene keelest laenatud. Laenuallikaks sobib vene mpястú 'raputama, loksutama, väristama, värisema $\mathrm{v}$ vappuma $\mathrm{v}$ vaplema $\mathrm{v}$ vabisema panema, põrutama', oleviku ainsuse 1. pööre mpяcý, 3. pööre mpясёm, käskiva kõneviisi ainsuse 2. pööre тряси́ (VES 2: 756). Häälikuline vastavus on ootuspärane: sõnaalgulisest konsonantühendist on säilinud ainult teine osis, vene rõhutule $\Omega$-le vastab 
eesti laensõnades harilikult lühike $\ddot{a}$, harvem $a$ (Must 2000: 525). Niisiis võiks kõnealusest vene tegusõnast olla saadud nii räsima kui ka rasima. Tüvevokaal $i$ võiks lähtuda vene käskivast kõneviisist. Semantiliselt on vene sõna samuti väga lähedane, võrreldagu paari sõnaraamatu kasutusnäidet: трясти́ яблоню 'õunapuud raputama', трясти́ за плечо 'õlast raputama' (VES 2: 756); Тряси жену, как грушу, а люби ее, как душу! ['Raputa naist nagu pirni(puud), aga armasta teda nagu hinge!'] (Dal' 1955: 439).

Omaette küsimuseks jääb sõnade räsima ja resima murdeliste kõrvaltähenduste päritolu ja vahekord. Sõnal räsima on lisaks kirjakeelsetega sarnastele murrakuti registreeritud veel tähendusi 'kisklema, naaklema, riidlema; lõikama; närima; püüdlikult, ent tulemusvaeselt töötama, pingutades tegema; pilkama, arvustama' (EMSUKA). Sõnal resima on põhitähendusele 'lõikama' lisaks tähendused 'tõmbama, sikutama; rüselema; kisklema' (EMSUKA). Näib, et osaliselt on kahe eri laenuallikast pärit sõna variandid kokku langenud. Eesti murretes on täheldatud $\ddot{a}$ ja $e$ vaheldust (vt nt Kask 1980: 32). Näiteks räsima 'lõikama' on pigem resima 'lõikama' häälikuline variant kui räsima 'raputama, sasima' eritähendus. resima tähendused 'tõmbama, sikutama; rüselema; kisklema' näivad jällegi rohkem seostuvat räsima tähendustega 'sasima, rebima; haarama' kui lõikamisega. Ei saa välistada, et siin on kuigivõrd tähendust mõjutanud saksa reißen 'kiskuma, rebima, tõmbama, sikutama; katki kiskuma (v rebima); vigastama, kriimustama; (maha) murdma; rebenema, kärisema, katkema, katki minema'; sich reißen KõNEK 'kaklema, kisklema' (SES: 977). Lisaks on räsima ja resima kõrval murretes häälikuliselt ja tähenduselt lähedased räis(s)ima 'sasima, sõtkuma, rikkuma; prahti täis ajama' ja räüssäm $(m)$ ä 'lamandama, maha peksma' (EMSUKA), mille päritolu on seni ebaselge. See teema vajab kindlasti täiendavat uurimist. Sellele vaatamata võib tõdeda, et sõnad räsima ja rasima kuuluvad etümoloogiliselt kokku ja lähtuvad mõlemad vene tegusõnast mрястú, olles niiviisi laenatud teisest allikast kui murdesõna resima.

Uurimust on toetanud Eesti Teadusfondi grant ETF9367 „Eesti tüvevara diakroonilised ja areaalsed seosed".

Murded ja murrakud:

Ambla; Audru; Hanila; Helme; I = idamurre; IisR = Iisaku (rannikumurre); JõeK = Jõelähtme (keskmurre); Jõhvi; Kambja; Kanepi; Keila; KJn = Kolga-Jaani; Kod = Kodavere (idamurre); Koeru; Kose; Kse = Karuse; Ksi = Kursi; Kullamaa; Kuu = Kuusalu (rannikumurre); KuuK = Kuusalu (keskmurre); Laiuse; LNg = LääneNigula; Lüganuse; M = Mulgi murre; Martna; Muhu; Otepää; Phl = Pühalepa; Pilistvere; PJg = Pärnu-Jaagupi $;$ Plt = Põltsamaa; Plv = Põlva $;$ Pst $=$ Paistu; Puhja; Rannu; Ridala; Rõngu; Rõuge; Räpina; Sangaste; Simuna; Tõstamaa; Varstu; VJg = Viru-Jaagupi; VNg = Viru-Nigula; Võnnu; Äksi.

\section{Arhiivimaterjalid}

EMSUKA = Eesti murrete ja soome-ugri keelte arhiiv Tallinnas Eesti Keele Instituudis. 


\section{Kirjandus}

Blokland, Rogier 2009. The Russian Loanwords in Literary Estonian. (Veröffentlichungen der Societas Uralo-Altaica 78.) Wiesbaden: Harrassowitz Verlag.

D a l' 1955 = Владимир Даль, Толковый словарь живого великорусского языка. Том IV, P-V. Москва: Государственное издательство иностранных и национальных словарей. [1. $\operatorname{tr} 1882$.

EES = Iris Metsmägi, Meeli Sedrik, Sven-Erik Soosaar 2012. Eesti etümoloogiasõnaraamat. Eesti Keele Instituut. Tallinn: Eesti Keele Sihtasutus.

EEW = Julius Mägiste 1982-1983. Estnisches etymologisches Wörterbuch. Helsinki: Finnisch-Ugrische Gesellschaft.

EKSS = Eesti keele seletav sõnaraamat. Toim Margit Langemets, Mai Tiits, Tiia Valdre, Leidi Veskis, Ülle Viks, Piret Voll. Eesti Keele Instituut. Tallinn: Eesti Keele Sihtasutus, 2009.

EMS = Eesti murrete sõnaraamat. I-V. Eesti Teaduste Akadeemia, Eesti Keele Instituut. Tallinn: Eesti Keele Sihtasutus, 1994-2013.

EWD = Etymologisches Wörterbuch des Deutschen. 2. Auflage, durchgesehen und ergänzt von Wolfgang Pfeifer. Berlin: Akademie Verlag, 1993. [1. tr 1989.]

DWB = Das Deutsche Wörterbuch von Jacob und Wilhelm Grimm auf CD-ROM und im Internet. http://germazope.uni-trier.de/Projekte/DWB (13. XI 2015).

Ha ak, Anu 1990. Baltisaksa keele kajastusi eesti murrete sõnavaras. - Keel ja Kirjandus, nr 6, lk 353-355.

Hu pel, August Wilhelm 1818. Ehstnische Sprachlehre für die beyden Hauptdialekte, den revalschen und dörptschen, nebst einem vollständigen ehstnischen Wörterbuche. Mitau: J. F. Steffenhagen und Sohn.

Kask, Arnold 1980. Eesti keele ajalooline grammatika. 2. vihik. Häälikulugu. Tartu: Tartu Riiklik Ülikool, eesti keele kateeder.

Mus t, Mari 2000. Vene laensõnad eesti murretes. Tallinn: Eesti Keele Sihtasutus. R a u n, Alo 1982. Eesti keele etümoloogiline teatmik. Rooma-Toronto: Maarjamaa. SES = Elisabeth Kibbermann, Salme Kirotar, Paula Koppel. Saksa-eesti sõnaraamat. Deutsch-estnisches Wörterbuch. Toim ja täiend Anne Arold, Mari Tarvas, Mari-Ann Palm. Tallinn: Valgus, 2007.

VES 2 = Vene-eesti sõnaraamat. Русско-эстонский словарь 2. Teine, parandatud trükk. Toim Helle Leemets, Henn Saari, Rein Kull. Eesti Keele Instituut. Tallinn: Eesti Keele Sihtasutus, 2000.

Viires, Ants 1960. Eesti rahvapärane puutööndus. Ajalooline ülevaade. Eesti NSV Teaduste Akadeemia Ajaloo Instituut. Tallinn: Eesti Riiklik Kirjastus.

Wi e d e m a n n, Ferdinand Johann 1973 [1893]. Eesti-saksa sõnaraamat. Neljas, muutmata trükk teisest, Jakob Hurda redigeeritud väljaandest. Tallinn: Valgus. 


\section{Two younger loanwords in Estonian}

Keywords: lexicology, etymology, German loanwords, Russian loanwords, Estonian

The article discusses the origin of the Estonian words klopp 'block of wood'; dial. 'piece of wood; block-shaped (part of) object' and räsima 'shake up, entangle, tear (and hurt); disfigure by trampling or crushing etc; grab, grasp'. The word klopp is a German loanword, < Gm Kloben, Klobe 'block of wood, split billet; small planing bench; hook; door hinge', with the original general meaning 'split object'. The same stem occurs in the dialectal compound kloopsaag, kloppsaag 'two-man saw for longitudinal sawing of boards and planks' < Gm Klobensäge, Klobsäge id. The word räsima with identical meaning is a Russian loanword, < Rus mрястú 'shake, jiggle, make jiggle, jolt', $1^{\text {st }}$ person present singular mрясý, $2^{\text {nd }}$ person singular imperative mряси́. The back-vowelled rasima derives from the same Russian source.

Iris Metsmägi (b. 1968), PhD, Institute of the Estonian Language, Senior Lexicographer,iris.metsmagi@eki.ee 